which is reported to occur in as many as $70 \%$ of cases. ${ }^{1314}$

Our patient was managed conservatively because of his haemodynamic stability and minimal peritoneal signs. When his condition gradually worsened, a laparotomy was considered too hazardous because of the coagulation disorder and the multiple intra-abdominal hamartomas. Urgent angiography was performed, and embolisation of the splenic artery was possible, completely controlling the haemorrhage.

Arterial embolisation is not routinely used in controlling intra-abdominal bleeding following trauma. A few reports mention its use in treating bleeding from post-traumatic pseudoaneurysms ${ }^{15}$ or splenic trauma in a patient with hepatic cirrhosis. ${ }^{13}$ Only one report mentions its limited role in patients who are a poor operative risk. ${ }^{16}$

This case illustrates the possible role of therapeutic angiography in the management of splenic trauma in the presence of major drawbacks to surgery.

1 Wiedemann HR, Burgio GR, Aldenhoff P, et al. The proteus syndrome. Partial gigantism of the hands and/or feet, nevi, hemihypertrophy, subcutaneous tumors, macrocephaly or other skull anomalies and possible accelerated growth and visceral affections. Eur J Pediatr 1983;140:5-12.

2 Vaughn RY, Selinger AD, Howell CG, et al. Proteus syndrome: diagnosis and surgical management. J Pediatr Surg $1993 ; 28: 5-10$
3 Tibbles JA, Cohen MM. The Proteus syndrome: the Elephant Man diagnosed. BMJ 1986;293:683-5.

4 Kruger G, Pelz L, Wiedemann HR. Transmission of Proteus syndrome from mother to son? Am J Med Genet 1993;45: $117-8$.

5 Goodship J, Redfearn A, Milligan D, et al. Transmission of Proteus syndrome from father to son? J Med Genet 1991; 28:781-5.

6 Rudolph G, Blum WF, Jenne EW, et al. Growth hormone (GH), insulin-like growth factors (IGFs), and IGF-binding protein-3 (IGFBP-3) in a child with Proteus syndrome. Am J Med Genet 1994;50:204-10.

7 Vaughn RY, Lesher JL, Chandler FW, et al. Histogenesis of vascular tumors in the Proteus syndrome. South Med J 1994;87:228-82.

8 Mucha P, Daly RC, Farnell MB. Selective management of blunt splenic trauma. J Trauma 1986;26:970-9.

9 Smith JS, Wengrovitz MA, DeLong BS. Prospective validation of criteria, including age, for safe nonsurgical managetion of criteria, including age, for safe nonsurgical mana

10 Kohn JS, Clark DE, Isler RJ, et al. Is computed tomographic grading of splenic injury useful in the nonsurgical managment of blunt trauma? J Trauma 1994;36:385-9.

11 Cogbill TH, Moore EE, Jurkovich GJ, et al. Nonoperative management of blunt splenic trauma: a multicenter experience. J Trauma 1989;29:1312-7.

12 Longo WE, Baker CC, McMillen MA, et al. Nonoperative management of adult blunt splenic trauma. Ann Surg $1989 ; 210: 626-9$

13 Nallathambi MN, Ivatury RR, Wapnir I, et al. Nonoperative management versus early operation for blunt splenic trauma in adults. Surg Gynecol Obstet 1988;166:252-8.

14 Rappaport W, McIntyre KE, Carmona R. The managemen of splenic trauma in the adult patient with blunt multiple iniuries. Surg Gynecol Obstet 1990;170:204-8.

$15 \mathrm{Kahn}$ AB, Reid AW. Management of renal stab wounds by arteriographic embolization. Scand J Urol Nephrol 1994 28:109-10.

16 Scalfani SJ, Shaftan GW, Phillip TF, et al. Percutaneous transcatheter arterial embolization. J Trauma $1985 ; 25$ 1021-9.

\title{
An unusual cause of rib fracture following a road traffic accident
}

\author{
R J Daniels, R A Fulcher
}

\begin{abstract}
A case is presented which is thought to be the first described example of rib fracture occurring as a result of airbag inflation. It would appear that the propellant cartridge came loose during deployment to form a missile, striking the patient on his chest and fracturing a rib.

( 7 Accid Emerg Med 1997;14:113-114)
\end{abstract}

Royal Devon and Exeter Hospital,

Barrack Road, Exeter

EX2 5DW, United

Kingdom

R J Daniels

Department of

Medicine for the

Elderly, Norfolk and

Norwich Hospital,

Brunswick Road,

Norwich NR1 3SR,

United Kingdom

R A Fulcher

Correspondence to:

Dr R J Daniels, 9 Mile End

Road, Norwich NR4 7QY.

Accepted for publication 18 September 1996
Keywords: airbag; airbag related injury; rib fracture.

\section{Case report}

The patient, a 73 year old asthmatic, was driving a 1994 Ford Mondeo 1.8 LX estate when he was involved in a low velocity frontal collision with another vehicle. The patient was wearing a seatbelt and the impact caused his air bag to inflate. Immediately after the impact, the patient felt a sharp blow on the left side of his chest. He received no other injuries. He was admitted to hospital complaining of chest pain, shortness of breath, and difficulty in breathing.

Examination of his chest revealed reduced expansion bilaterally, basal crepitations, and focal tenderness over his left anterolateral chest wall. Breath sounds were vesicular and no wheeze was heard. The jugular venous pulse was not raised and the trachea was central. Peak expiratory flow rate was 180 litres $/ \mathrm{min}$, compared with a normal value of 300 litres/ min for this patient. An ECG showed no acute ischaemic changes and arterial blood gases on air were normal. A chest $x$ ray was taken of the patient which showed a fracture of the left ninth rib laterally (fig 1). The patient was treated with analgesia, and admitted overnight for observation. He made an uneventful recovery and was discharged the following day.

Close examination of the clothes that this patient was wearing at the time of the crash revealed a hole approximately $1.5 \mathrm{~cm}$ in diameter surrounded by a chemical residue in a position overlying the site of the fracture (figs 2 and 3). Unfortunately it was not possible for chemical analysis to be performed on this residue. The patient reported that the coat was undamaged before the accident.

\section{Discussion}

Many studies have shown the benefits of airbags as a passenger restraint system, particularly in conjunction with seatbelts, where their use has been estimated to reduce fatalities by 


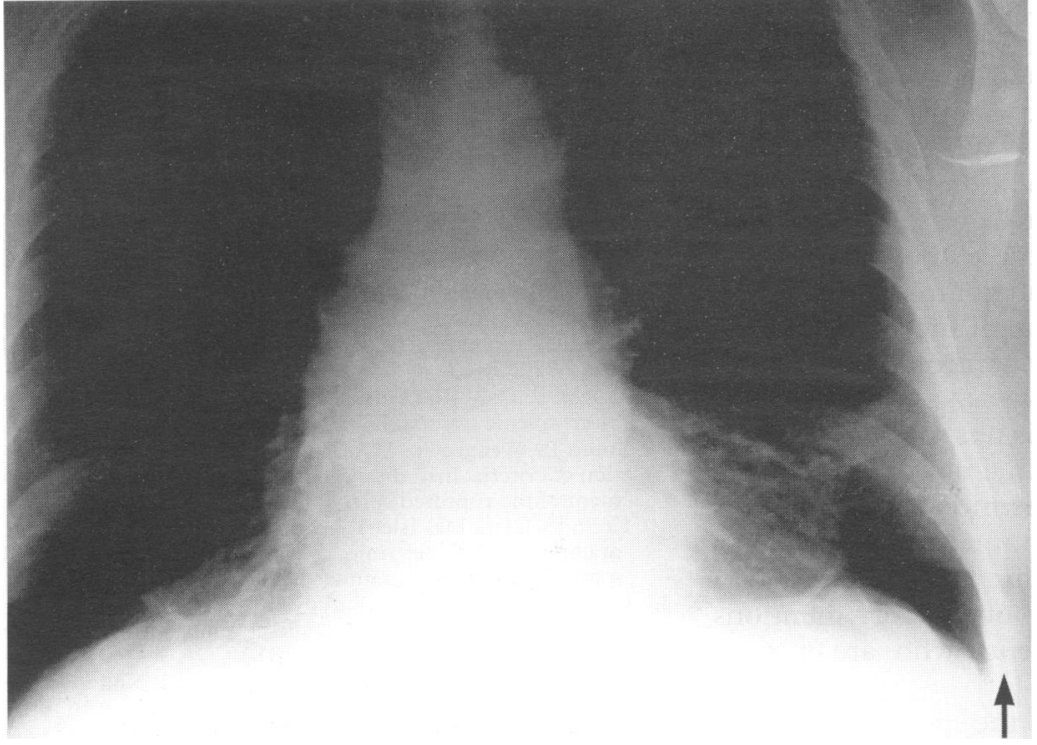

Figure 1 Chest radiograph showing fracture of left ninth rib laterally (arrowed).

up to $24 \% .^{1}$ The rise in availability of airbags in cars has, however, also seen the development of a new phenomenon, that of airbag trauma.

This patient sustained a fracture of his rib after apparently being struck by a component of his airbag shortly after deployment in a frontal collision. We believe this to be the first reported case of an airbag inflation mechanism causing a fractured rib. The occurrence of this injury in a patient whose respiratory reserve was already significantly compromised by his asthma resulted in a potentially serious combination of airway restriction and obstruction, in an otherwise trivial collision.

Air bags are designed to be deployed rapidly by deceleration sensors igniting a solid rocket propellant which produces a large volume of gas. The propellant capsule is mounted in a steel cup and it appears that this capsule had come loose during deployment to form a high velocity missile, striking the patient on his chest and fracturing his ninth rib. This hypothesis is further supported by the finding of solid fuel residues around the impact site on the patient's clothing.

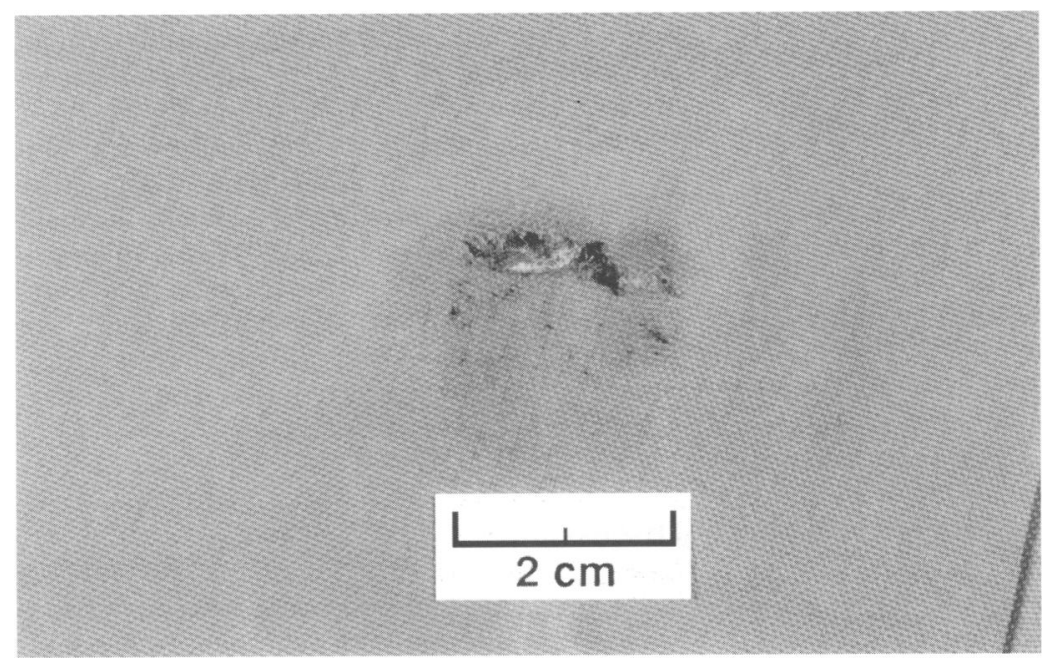

Figure 3 Close up view of hole, showing chemical residues.

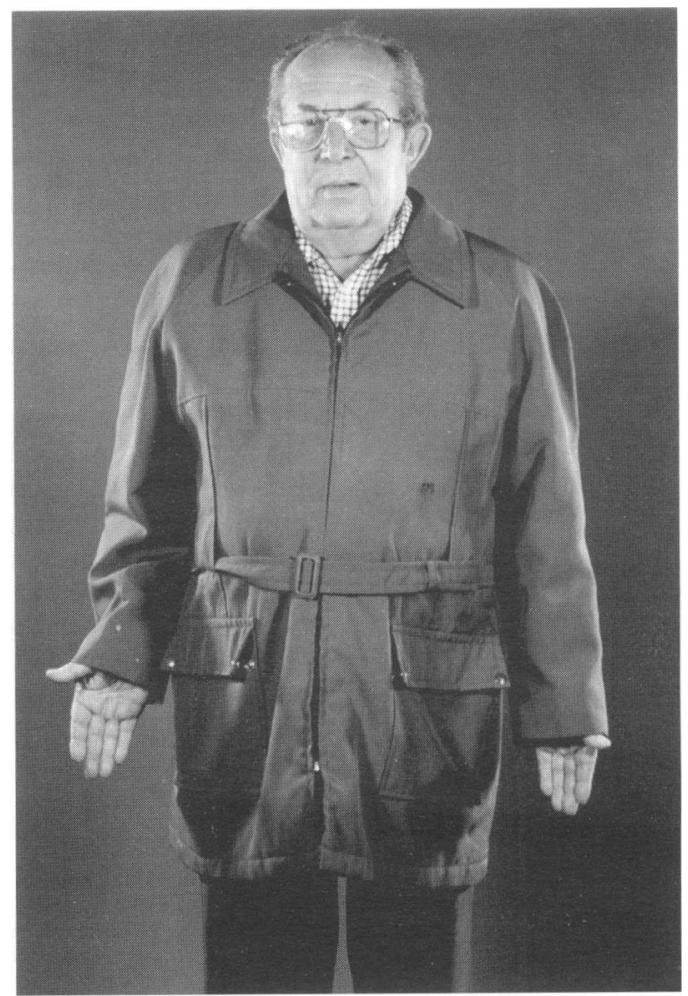

Figure 2 Damaged clothing overlying fracture site.

Other reported injuries caused by airbags include those caused by mechanical components such as the airbag module cover, which has been shown to reach speeds of up to 144 mph during deployment. ${ }^{2}$ One paper describes three such cases resulting in avulsion of the thumb at the metacarpophalangeal joint, multiple fractures of the upper limb including fracture dislocation of the elbow, and a subdural haematoma with subsequent respiratory arrest. $^{3}$ The forceful and rapid inflation of the airbag may fling the upper limb into the instrument panel, windscreen, or rear view mirror as well as cause contusions, abrasions, and sprains by the impact of the inflating airbag with the driver's body. ${ }^{4}$ Facial and ocular trauma have also been reported by both the inflating airbag and by the airbag forcing objects such as spectacles or tobacco pipes into the eye..$^{5-7}$

This case report illustrates that while continual improvements are made in occupant protection systems we are still some way from the ideal combination of maximum protection with minimum risk, and that in situations where the risk of injury due to the impact is low, morbidity and even mortality due to airbag deployment may become significant.

1 Lund AK, Ferguson SA. Driver fatalities in 1985-1993 cars with airbags. J Trauma 1995;38:469-75.

2 National Highway Traffic safety Administration. Air bag deployment characteristics. Springfield: National Technical Information Service, September 1992.

3 Smock WS, Nichols JR. Airbag module cover injuries. J Trauma 1995;38:489-93.

4 Huelke DF, Moore JL, Compton TW, Samuels J, Levine RS. Upper extremity injuries related to airbag deployments. J Trauma. 1995;38:482-8.

5 Larkin GL. Airbag mediated corneal injury. Am J Emerg Med 1991;9:444-6.

6 Gault JA, Vichnin MC, Jaeger EA, Jeffers JB. Ocular injury associated with eyeglass wear and airbag inflation. Trauma.1995;38:494-7.

7 Walz FH, Mackay M, Gloor B. Airbag deployment and eye perforation by a tobacco pipe. J Trauma.1995;38:498-501. 